\title{
Glutamatergic deficits and parvalbumin-containing inhibitory neurons in the prefrontal cortex in schizophrenia BKY Bitanihirwe ${ }^{\dagger 1,5}$, MP Lim ${ }^{\dagger 1}$, JF Kelley ${ }^{1}$, T Kaneko ${ }^{4}$ and TUW Woo*1,2,3
}

Address: ${ }^{1}$ Laboratory of Cellular Neuropathology, McLean Hospital, Belmont, MA, USA, ${ }^{2}$ Department of Psychiatry, Harvard Medical School, Boston, MA, USA, ${ }^{3}$ Department of Psychiatry, Beth Israel Deaconess Medical Center, Boston, MA, USA, ${ }^{4}$ Department of Morphological Brain Science, Kyoto University, Kyoto, Japan and ${ }^{5}$ Laboratory of Behavioral Neurobiology, ETH Zurich, Schorenstrasse 16, Schwerzenbach 8603, Switzerland

Email: BKY Bitanihirwe - byron.bitanihirwe@behav.biol.ethz.ch; MP Lim - mlim@mclean.harvard.edu; JF Kelley - jkelley@mclean.harvard.edu; T Kaneko - kaneko@mbs.med.kyoto-u.ac.jp; TUW Woo* - wwoo@hms.harvard.edu

* Corresponding author †Equal contributors

Published: 16 November 2009

BMC Psychiatry 2009, 9:7| doi:I0.| I86/I47|-244X-9-7|
Received: 2 June 2009

Accepted: 16 November 2009

This article is available from: http://www.biomedcentral.com/|47/-244X/9/7|

(C) 2009 Bitanihirwe et al; licensee BioMed Central Ltd.

This is an Open Access article distributed under the terms of the Creative Commons Attribution License (http://creativecommons.org/licenses/by/2.0), which permits unrestricted use, distribution, and reproduction in any medium, provided the original work is properly cited.

\begin{abstract}
Background: We have previously reported that the expression of the messenger ribonucleic acid (mRNA) for the NR2A subunit of the N-methyl-D-aspartate (NMDA) class of glutamate receptor was decreased in a subset of inhibitory interneurons in the cerebral cortex in schizophrenia. In this study, we sought to determine whether a deficit in the expression of NR2A mRNA was present in the subset of interneurons that contain the calcium buffer parvalbumin (PV) and whether this deficit was associated with a reduction in glutamatergic inputs in the prefrontal cortex (PFC) in schizophrenia.
\end{abstract}

Methods: We examined the expression of NR2A mRNA, labeled with a ${ }^{35}$ S-tagged riboprobe, in neurons that expressed PV mRNA, visualized with a digoxigenin-labeled riboprobe via an immunoperoxidase reaction, in twenty schizophrenia and twenty matched normal control subjects. We also immunohistochemically labeled the glutamatergic axon terminals with an antibody against vGluTI.

Results: The density of the PV neurons that expressed NR2A mRNA was significantly decreased by $48-50 \%$ in layers 3 and 4 in the subjects with schizophrenia, but the cellular expression of NR2A mRNA in the PV neurons that exhibited a detectable level of this transcript was unchanged. In addition, the density of vGluTI-immunoreactive boutons was significantly decreased by $79 \%$ in layer 3, but was unchanged in layer 5 of the PFC in schizophrenia.

Conclusion: These findings suggest that glutamatergic neurotransmission via NR2A-containing NMDA receptors on PV neurons in the PFC may be deficient in schizophrenia. This may disinhibit the postsynaptic excitatory circuits, contributing to neuronal injury, aberrant information flow and PFC functional deficits in schizophrenia.

\section{Background}

The prefrontal cortex (PFC) plays an important role in the temporal organization of behavior $[1,2]$ by temporarily maintaining "on-line" internal representations of perceptual, cognitive and emotive information in order to guide sequential, contextually meaningful behavior [3]. This 
"executive functioning" capacity forms the basis of many daily human activities, such as planning, reasoning and thinking, and is known to be impaired in patients with schizophrenia [4].

Sustained discharge of neuronal circuits is thought to be the physiological substrate that mediates on-line maintenance and manipulation of information performed by the PFC $[1,2]$. Inhibitory neurons that utilize $\gamma$-aminobutyric acid (GABA) as neurotransmitter play a key role in regulating sustained neuronal activation by dynamically adjusting the conductances of the pyramidal neuronal network. Importantly, the number of $\mathrm{N}$-methyl-D-aspartate (NMDA) glutamate receptors within a neural network, including those that are localized on GABA neurons, appears to be a critical determinant of the stability of the network in sustaining neuronal activation [5-9]. GABA neurons receive feedback excitatory modulation via local recurrent excitatory projections from the pyramidal neurons they innervate and, at the same time, they are also targets of feedforward excitatory modulation from axonal projections furnished by other pyramidal neurons, located both within the PFC and in other cortical areas [10-12]. The integrity of PFC functions therefore depends on the delicate interplay of feedback and feedforward mechanisms of modulation of cortical inhibitory activities via activation of glutamate receptors on GABA interneurons $[8,9,13,14]$.

There has been compelling evidence suggesting that GABA neurons in the PFC are functionally disturbed in schizophrenia [15-18]. In addition, disturbances of glutamatergic modulation of these neurons could further compromise their normal functioning. In fact, we have recently found that, in both the PFC and anterior cingulate cortex, the expression of the mRNA for the NR2A subunit of the NMDA glutamate receptor was decreased to a level that was no longer experimentally detectable in 49$73 \%$ of the GABA neurons that normally expressed this transcript in subjects with schizophrenia $[19,20]$. Because connectionally and functionally distinct subpopulations of GABA neurons regulate different aspects of information flow in the cerebral cortex [21-23], an important question that must be addressed in order to truly appreciate the pathophysiologic consequences of altered glutamatergic modulation of GABA neuronal functions in schizophrenia is the identity of the GABA cells that are affected.

Increasing evidence suggests that the subset of GABA cells that contain the calcium buffering protein parvalbumin $(\mathrm{PV})$, which exhibit fast-spiking firing properties and target the perisomatic (basket cells) and axo-axonic (chandelier cells) compartments of pyramidal neurons $[24,25]$, are functionally disturbed in schizophrenia $[17,26]$, and these cells express NR2A [27-29]. In this study, using dou- ble in situ hybridization, we found that the density of NR2A mRNA-expressing PV neurons was decreased by as much as $50 \%$ in subjects with schizophrenia in a layerspecific manner. In addition, we immunohistochemically labeled glutamatergic terminals with an antibody against the vesicular glutamate transporter vGluT1 $[30,31]$. We found that the density of these terminals also exhibited a reduction with a laminar pattern that paralleled the reduction in the NR2A-expressing PV neurons. Together these observations suggest that glutamatergic innervation of PVcontaining inhibitory neurons appears to be deficient in schizophrenia.

\section{Methods \\ Human Subjects}

Post-mortem brains from subjects whose next of kin had given consent for their tissues to be used in medical research were obtained from the Harvard Brain Tissue Resource Center at McLean Hospital, Belmont, Massachusetts. The informed consent process has been approved by the McLean Hospital Human Research Committee. Comparison group brains were collected from subjects diagnosed with schizophrenia $(n=20)$ and normal control subjects $(n=20)$ matched for age, postmortem interval (PMI), brain $\mathrm{pH}$ and wherever possible, sex and hemispheric laterality. All brains were examined by a neuropathologist to rule out any neurologic conditions (Additional file 1).

Diagnosis of schizophrenia was made by reviewing medical records and an extensive family questionnaire that included medical, psychiatric and social history. Two psychiatrists (Drs. T.-U. W. Woo and F. M. Benes) reviewed all records and applied the criteria of Feighner et al. [32] for the diagnosis of schizophrenia and DSM III-R criteria for the diagnosis of schizoaffective disorder. Seventeen of the 20 schizophrenia subjects were on antipsychotic medications at the time of death. Some of these subjects were receiving concomitant psychotropic medications, such as anticonvulsants, mood stabilizers, antidepressants or anxiolytics (Additional file 1). None of the normal control subjects was on any psychotropics at the time of death. Toxicology data together with clinical information confirmed that none of the subjects in each group suffered from any substance-related disorders at the time of death.

\section{Double In Situ Hybridization}

Tissue Preparation

Tissue blocks, each about $3 \mathrm{~mm}$ in thickness, were removed from Brodmann's Area 9 of fresh brain specimens and fixed in $0.1 \%$ paraformaldehyde in ice-cold 0.1 phosphate buffer saline (PBS; pH 7.4) for 90 minutes, immersed in $30 \%$ sucrose in the same buffer overnight, and then frozen in Tissue Tek OCT (Sakura Finetek, Torrance, CA). Sections of $10 \mu \mathrm{m}$ were cut on a cryostat, 
mounted on slides, and stored at $-70^{\circ} \mathrm{C}$ until use. Two sections per subject were used for in situ hybridization.

\section{Riboprobe Preparation}

Radiolabeled $c R N A$ probe for NR2A

The complementary RNA (cRNA) probes were transcribed in vitro from full-length complementary DNA (cDNA) clones of the rat NR2A (Genbank Accession No. M91561) subunit (kindly provided by Dr. Christine Konradi), which is $89 \%$ identical to the human sequence, as described previously $[19,20]$. This same riboprobe was used in our previously published studies $[19,20,33]$. Briefly, the probe was derived from a cDNA spanning nucleotides 1185 to 2154 within the coding region of the gene. A corresponding sense probe was also generated and hybridization of the sense probe resulted in no specific labeling. Radiolabeled cRNA was prepared by first drying down ${ }^{35}$ S]UTP $(500 \mathrm{mCi} / \mathrm{ml}$ of probe, Perkin Elmer Life and Analytical Sciences Inc, Boston, Mass) in a DNA Speed-Vac (Savant, Farmingdale, NY). $100 \mathrm{ng} / \mathrm{ml}$ of the cDNA template, $0.1 \mathrm{M}$ dithiothreitol (DTT), $3 \mathrm{U} / \mathrm{ml}$ of RNasin, $5 \mathrm{mM}$ NTPs, $0.8 \mathrm{U} / \mathrm{ml} \mathrm{T3}$ or T7 polymerases (for antisense and sense probe respectively), and $5 \times$ transcription buffer were then added. The transcription mixture was subsequently incubated at $37^{\circ} \mathrm{C}$ for 2 hours. The cDNA template was digested by incubating the mixture with R1Q DNAse at $37^{\circ} \mathrm{C}$ for 15 minutes. Unincorporated NTPs were removed by running the mixture through a Stratagene Nuc-Trap (La Jolla, CA) push column. The eluate was collected, and probe concentration was determined by scintillation counting. The probe was stored at $20^{\circ} \mathrm{C}$ until use.

\section{Digoxigenin (DIG)-labeled cRNA probe for PV}

A single PCR product of $510 \mathrm{bp}$ (spanning nucleotides 51560 ) within the coding region of the human parvalbumin gene (Genbank Accession No. NM 002854.2) was amplified from human brain cDNA. DIG-UTP-labeled cRNA probes were transcribed using $100 \mathrm{ng}$ of linearized parvalbumin cDNA subclones in the presence of $0.1 \mathrm{M}$ DTT, 3 $\mathrm{U} / \mathrm{ml}$ RNasin, $0.8 \mathrm{U} / \mathrm{ml}$ of T3 and T7 RNA polymerases, $10 \mathrm{mM}$ of ATP, CTP, and GTP, $6.5 \mathrm{mM}$ of UTP, and 3.5 $\mathrm{mM}$ of DIG-labeled UTP (Roche, Indianapolis, IN). The mixture was incubated at $37^{\circ} \mathrm{C}$ for 2 hours. cDNA template was digested with RQ1 DNase. The sense probe was also generated as control.

\section{Hybridization}

Sections were hybridized in a buffer consisting of 50\% formamide, $0.1 \%$ yeast transfer $(\mathrm{t}) \mathrm{RNA}, 10 \%$ dextran sulfate, $1 \times$ Denhardt's solution, $0.5 \mathrm{M} / \mathrm{l}$ ethylenediamine tetracetic acid (EDTA), $0.02 \%$ sodium dodecyl sulfate (SDS), $4 \times$ saline-sodium citrate buffer (SSC), $10 \mathrm{mM}$ dithiothreitol (DTT), and $0.1 \%$ single stranded DNA (ssDNA) at a final concentration of $0.4 \mathrm{ng}$ probe/ml hybridization buffer. They were then post-fixed in $4 \%$ paraformaldehyde for 10 minutes and incubated in $0.1 \mathrm{M}$ triethanolamine (TEA) for 5 minutes at room temperature before being dehydrated in a graded series of ethanol. Probes were then added to slides for hybridization in a prewarmed, humidified dish. Sections were covered with coverslips and incubated at $56^{\circ} \mathrm{C}$ for 12 hours in a humid chamber. At the end of hybridization, coverslips were soaked off in $4 \times$ SSC in the presence of $100 \mu \mathrm{l}$ of $\beta$-mercaptoethanol ( $\beta$ Mer). Tissue was then incubated in $0.5 \mathrm{M}$ $\mathrm{NaCl} / 0.05 \mathrm{M}$ phosphate buffer for 10 minutes, $0.5 \mathrm{M}$ $\mathrm{NaCl}$ with $0.025 \mathrm{mg} / \mathrm{ml} \mathrm{RNaseA}$ at $37^{\circ} \mathrm{C}$ for 30 minutes, followed by a high stringency wash with a solution containing $50 \%$ formamide, $0.5 \mathrm{M} \mathrm{NaCl} / 0.05 \mathrm{M}$ phosphate buffer, and $100 \mathrm{ml} \beta \mathrm{Mer}$ at $63^{\circ} \mathrm{C}$ for 30 minutes. Sections were finally washed overnight in $0.5 \times$ SSC with $20 \mathrm{mM}$ $\beta$ Mer at room temperature.

\section{Visualization of DIG labeling}

After incubation in blocking buffer $(100 \mathrm{mM}$ Tris- $\mathrm{HCl}$, $150 \mathrm{mM} \mathrm{NaCl}[\mathrm{pH} 7.5])$, the sections were placed in buffer containing 3\% normal donkey serum $+0.3 \%$ Triton X100), and incubated overnight at $4^{\circ} \mathrm{C}$ in buffer containing 1:200 dilution of sheep anti-DIG antibody conjugated with peroxidase enzyme (Roche Diagnostics, Indianapolis, IN). Sections were washed in buffer and a peroxidase reaction product was localized 3,3'-diaminobenzidine tetrahydrochloride in the presence of $\mathrm{H}_{2} \mathrm{O}_{2}$.

\section{Emulsion Autoradiography}

Slides were apposed to X-ray film (Kodak Biomax MS) for 10 days to determine the presence of sufficient autoradiographic signal. The microscope slides were then dipped in emulsion, dried and exposed at $4{ }^{\circ} \mathrm{C}$ in the dark for 5 weeks. They were then developed in Kodak D-19 developer, counterstained and coverslipped.

\section{Quantification of Cell Density}

The slides were coded so that the diagnosis of each case was unknown to the investigator (BKYB). [ ${ }^{35}$ S]-labeling of NR2A mRNA appeared as clusters of silver grains after emulsion autoradiography processing. Quantification was performed as previously described $[19,20,33,34]$. DIG labeling, in the form of a brown reaction product, was visualized under a bright field microscope equipped with polarizing filters to enhance the optical density of the reaction product. Neurons that were single labeled with DIG and those that were double labeled with DIG and $\left.{ }^{35} \mathrm{~S}\right]$ were identified on images captured on a computer screen using a microscope (Laborlux, Leica Microsystems, Wetzlar, Germany) fitted with a solid CCD video camera and connected to a Bioquant Nova Image Analysis System (R\&M Biometrics, Memphis, TN). A touch counting subroutine was used to determine the distribution of both single and double-labeled neurons within a $250 \mu \mathrm{m}$-wide 
cortical traverse extending from the pial surface to the white matter border by using a X100 oil immersion objective lens at a final magnification of 1,000x. Two cortical traverses per section and therefore four cortical traverses per case were analyzed. For each case, cell counts averaged from the four cortical traverses were used in statistical analysis, so that each individual had only one representative measurement at each cortical depth. Neighboring sections were stained with cresyl violet for determination of laminar boundaries. Densities of both single and doublelabeled neurons for each cortical layer were then obtained by dividing cell counts by laminar areas. Prior to the actual data collection, intrarater reliability, as assessed by counting and recounting profiles in the same column, was established to be above $95 \%$.

To quantify the expression level of mRNA for the NR2A subunit in individual PV cells, the area occupied by each grain cluster was carefully outlined using a cursor displayed on the computer monitor, as previously described $[19,20,33,34]$. The cluster area was measured by highlighting the grains with a thresholding subroutine. All parameters were held constant throughout the entire course of quantification. The area covered by autoradiographic grains within the cluster area was automatically computed by the Bioquant software based on the threshold value and was represented as a pixel count for NR2A transcript expression level. The pixel count was expressed as a function of cluster area after correcting for background (i.e. pixel count of the area covered by autoradiographic grains per unit area in square micrometers in the white matter). The average NR2A expression level in PV neurons was computed for each cortical layer.

\section{vGluTI Immunohistochemistry}

Tissue blocks containing Brodmann's Area 9 were fixed in ice cold $4 \%$ paraformaldehyde overnight, cryoprotected in $30 \%$ sucrose, embedded in Tissue Tek OCT (Sakura Finetek, Torrance, CA), and sectioned at $40 \mu \mathrm{m}$ on a microtome. The entire experiment was completed in 2 runs. During each run, two sections per subject were used and all sections from each subject pair were processed together. Free-floating sections were rinsed for $15 \mathrm{~min}$ in $0.3 \% \mathrm{H}_{2} \mathrm{O}_{2}, 0.5 \%$ Triton- $\mathrm{X}$, and $10 \%$ methanol in PBS. They were then pre-incubated for 30 minutes in $5 \%$ normal horse serum and $0.3 \%$ Triton-X in PBS. Sections were subsequently incubated at room temperature overnight in a polyclonal rabbit anti-vGluT1 antibody (1:1000) diluted in $2 \%$ normal horse serum and $0.5 \%$ Triton-X in PBS. The specificity of the antibody has been extensively characterized [30,31,35,36]. After incubation, sections were rinsed in PBS and incubated at room temperature for 2 hours in biotinylated donkey anti-rabbit IgG (1:500; Jackson ImmunoResearch Laboratories, West Grove, PA) in $2 \%$ normal horse serum and $0.5 \%$ Triton X-100 in PBS.
They were then rinsed in PBS and incubated for 2 hours in ABC Elite (1:500; Vector Laboratories, Burlingame, CA) in PBS. vGluT1 elements were visualized with $0.4 \mathrm{mg} / \mathrm{mL}$ DAB (Sigma, St. Louis, MO), $0.0006 \%$ hydrogen peroxide, and $0.4 \mathrm{mg} / \mathrm{mL}$ nickel ammonium sulfate dissolved in PBS. Sections were mounted, air-dried, dehydrated, cleared in xylenes and coverslipped.

\section{Quantification}

All microscopic analyses were conducted under strictly blind condition. Sampling was performed in layers 3 and 5 within two $500 \mu \mathrm{m}$-wide traverses, $500 \mu \mathrm{m}$ apart from one another. Laminar boundaries were determined by comparing with neighboring Nissl-stained sections. Quantification was performed using a Leica Laborlux microscope equipped with a solid-state video camera and Bioquant Nova Image Analysis System. Using a X100 oil immersion objective lens, the areas covered by vGluT1immunoreactive boutons were outlined, computed and represented as pixel counts. Density measure per section was computed by averaging the measurements obtained from the two $500 \mu \mathrm{m}$-wide traverses. The density for each subject was obtained by averaging the measurements from all 4 sections.

\section{Statistical Analysis}

The densities of PV mRNA+ and PV mRNA+/NR2A mRNA+ neurons and the NR2A mRNA expression level in $\mathrm{PV}+$ neurons were compared between both groups across layers 2 through 6 using repeated-measures analysis of variance (ANOVA) with diagnosis and layer as main effects. Layer 1 was not included as no PV+ neurons were found in this layer. The density of vGluT1-immunoreactive boutons was compared between the two diagnosis groups, using unpaired t-tests. Analyses were performed using the JMP 5.1 (SAS Institute, Cary, NC) software program and all statistical tests were conducted with $\alpha=0.05$.

\section{Confounding Variables}

For both in situ hybridization and immunohistochemical experiments, we evaluated the effects of confounding variables, such as age, PMI, brain, $\mathrm{pH}$, freezer storage time and exposure to antipsychotic medication (expressed as chloropromazine equivalent dose or CED) using analysis of covariance (ANCOVA). Because none of the conclusions derived from our findings were affected by the ANCOVA analysis, only results from repeated-measures ANOVAs are reported. In addition, Pearson's correlation was used to assess if there was any linear relationship between cell, grain or vGluT1-immunoreactive bouton densities and any of the continuous variables. Effects of hemispheric laterality and sex were evaluated by using 2tailed unpaired $t$ tests to compare the measures from the two hemispheres within individual groups. 


\section{Results \\ Distribution of PV mRNA+ and PV mRNA+/NR2A mRNA+ Neurons}

Neurons that expressed PV mRNA were present predominantly in layers 3,4 and 5 and were also observed in layers 2 and 6 , but were absent from layer 1 . The PV mRNA+/ NR2A mRNA+ neurons seemed to be most concentrated in layers 3 and 4 (Figure 1).

\section{Density of PV mRNA+/NR2A mRNA+ Neurons}

The effect of diagnosis was significant $(F=6.62 ; \mathrm{df}=1,38$; $P=0.01)$. Furthermore, this effect was layer specific $(F=$ $3.75 ; \mathrm{df}=1,38 ; P=0.006$ ). Thus, in the subjects with schizophrenia, the density of the double-labeled neurons was significantly decreased by $48 \%$ and $50 \%$ in layers $3(t$ $=-2.11, P=0.04)$ and $4(t=-2.15, P=0.03)$, respectively (Figure 2).

\section{Density of PV mRNA+ Neurons}

Consistent with previous observations [26,37], we found that the number of cells that expressed a detectable level of PV mRNA was not altered in subjects with schizophrenia $(F=3.35 ; \mathrm{df}=1,38 ; P=0.07)$. The use of digoxigenin to label PV mRNA, however, precluded us from addressing any possible alteration in transcript expression level per neuron, as has been reported previously [26].

\section{Cellular Expression of NR2A mRNA}

The density of silver grains per neuron did not differ between the schizophrenia and normal control groups (Figure 3). Furthermore, the distributions of the frequency histograms of NR2A mRNA expression level per PV cell did not differ between the two study groups (data not shown). Taken together, it can be concluded that in the PV cells that expressed a detectable level of NR2A mRNA, the amount of transcript expression was unaltered in schizophrenia.

\section{vGluTI Immunoreactive Boutons}

The density of vGluT1-immunoreactive boutons in layer 3 of the PFC was significantly decreased by $79 \%$ in subjects with schizophrenia (Figure $4 ; t=2.07, P=0.05$ ).

\section{Confounding Variables}

Potential confounding variables (i.e. age, PMI, brain $\mathrm{pH}$, freezer storage time, hemispheric laterality, antipsychotic drug exposure, sex and laterality) were evaluated with respect to the densities of PV mRNA+ and PV mRNA+/ NR2A mRNA+ neurons, and vGluT1-immunoreactive boutons. None of these factors appear to have influenced our results.

\section{Discussion}

We have extended our previous finding of reduced NR2A mRNA expression in GABA neurons in schizophrenia
$[19,20]$ to demonstrate that, in the PFC, this reduction occurs in a subset of PV-containing neurons. Furthermore, the density of axonal boutons that were immunoreactive for vGluT1, which is localized to presynaptic terminals furnished by cortically-originated glutamatergic projections [30,31,38], also appears to be decreased. Together these observations suggest that innervation of PV neurons by corticocortical glutamatergic projections via NMDA receptors may be deficient in schizophrenia.

The observation of decreased density of the NR2Aexpressing PV neurons might represent a loss of these neurons, but previous studies suggest that cell loss does not seem to be a prominent feature in the PFC in schizophrenia, at least not in large scale $[39,40]$. Furthermore, consistent with previous observations [26,37], in this study, we found that the density of PV neurons was unaltered in schizophrenia subjects. Taken together, our finding is most consistent with the interpretation that, in a subset of PV neurons, the expression of NR2A is reduced to a level that is no longer experimentally detectable.

It has long been known that treatment with NMDA receptor antagonists produces a syndrome that is highly reminiscent of the clinical picture of schizophrenia [41,42], and these data led to the NMDA receptor hypofunction model [43]. The paradoxical excitotoxic effects originally observed by Olney and Farber with NMDA antagonists were explained, at least in part, by blockade of the NMDA receptors that are located on GABA neurons, which have been shown to be some 10-fold more sensitive to NMDA receptor antagonists than the NMDA receptor on pyramidal neurons [43-45]. To this end, a recent study by Kinney and colleagues found that the amount of NR2A mRNA expressed in cultured PV neurons was 5-fold higher than in pyramidal cells [27]. Similarly, compared to other NMDA subunits, the expression of NR2A appears to be prevalent in PV neurons [29]. Moreover, NR2A, but not NR2B selective antagonists, down-regulate $G_{A D}$ and PV mRNA expression in cultured PV neurons [27]. Finally, NMDA antagonism has been found to decrease the cellular expression of PV [46-48] and the number of axoaxonic cartridges [49]. Taken together, our finding of reduced NR2A expression in PV neurons may, at least in part, contribute to the reduction in the expression of $\mathrm{GAD}_{67}$ and PV and the decrease in the density of axon cartridges in schizophrenia [26,50-52].

The expression of the mRNA for vGluT1 has been found to be decreased in the PFC in schizophrenia [53], but negative results have also been reported [54]. At the protein level, using Western blot analysis, vGluT1 has been shown to be unaltered in the PFC, but decreased in the anterior cingulate cortex in schizophrenia [54]. In this study, we found that the density of the axonal boutons that were 

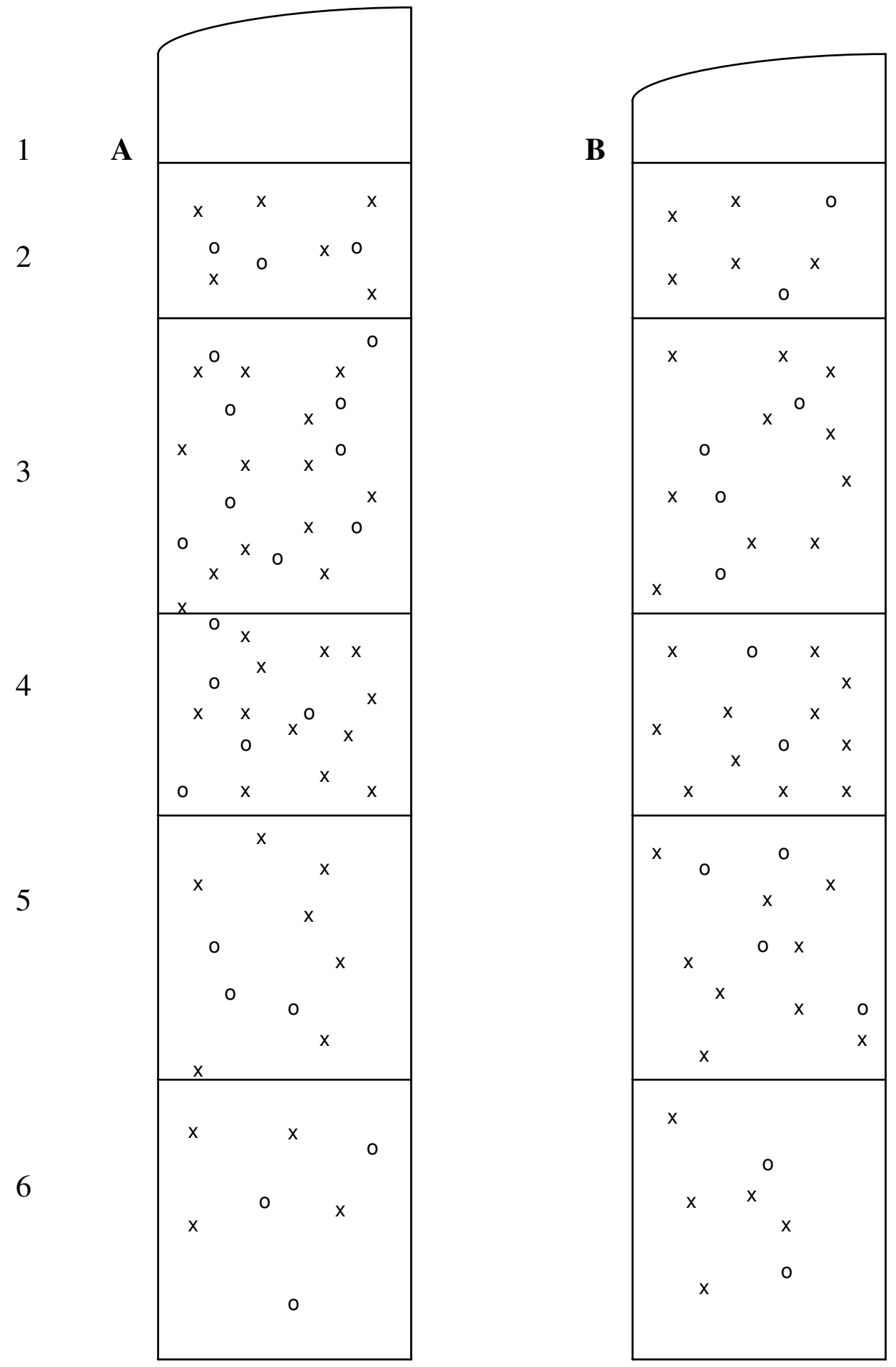

Figure I

Plots of PV+/NR2A+ neurons from representative sections from a normal control (A) and a schizophrenia subject (B). Numbers depict cortical layers. $X=P V m R N A$-expressing neurons. $O=P V$ neurons that co-express NR2A mRNA 

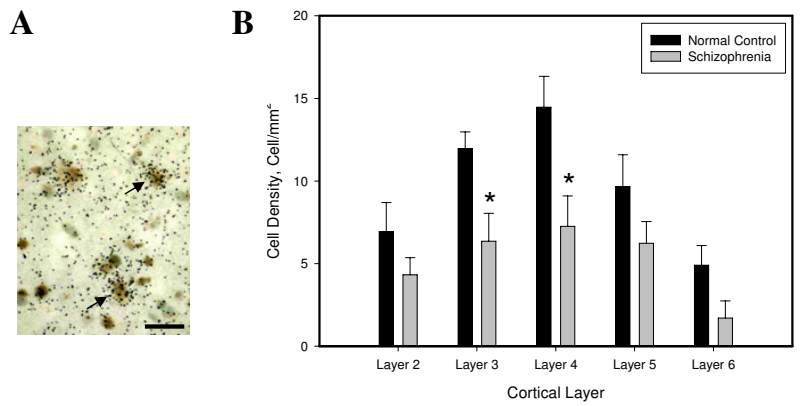

Figure 2

(A) Photomicrograph showing examples of PV+I

NR2A+ neurons. Scale bar $=20 \mu \mathrm{m}$. (B) Mean ( \pm SEM) density of $P V+/ N R 2 A+$ neurons is significantly decreased in layers 3 and 4 in the PFC in schizophrenia.

immunoreacvtive for vGluT1 was decreased in layer 3 of the PFC in subjects with schizophrenia. A likely explanation for the seeming discrepancy between this study and the previous report [54] may be attributable to methodological differences, i.e. immunohistochemistry in combination with quantification of axonal boutons afforded us a higher sensitivity in detecting differences in the present study. In the context of our finding, it is interesting to note that, a single polymorphism in the neuregulin-1 gene, a schizophrenia risk gene [55], has recently been reported to be associated with vGluT1 expression in human postmortem brains, with the at-risk allele predicting decreased expression of the glutamatergic marker [56].

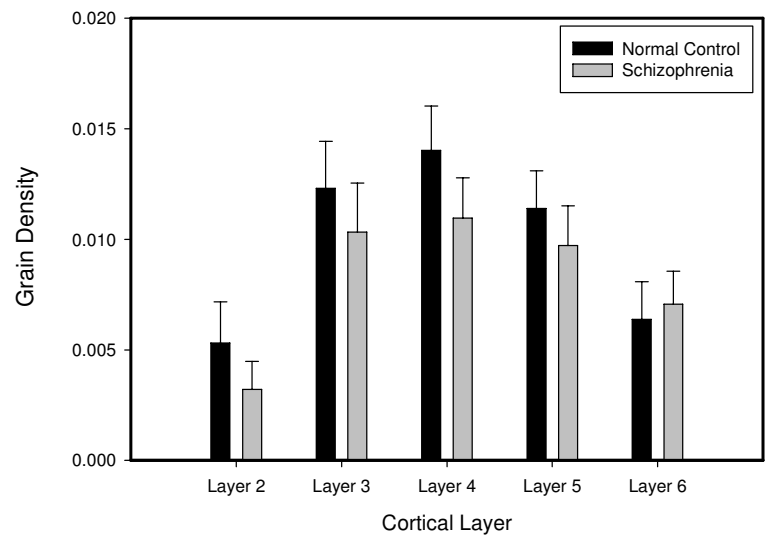

Figure 3

Mean ( \pm SEM) density of silver grains over PV+ neurons in the PFC is not different between the two subject groups, suggesting that the expression level of NR2A mRNA in PV cells is unchanged in schizophrenia.
A Control

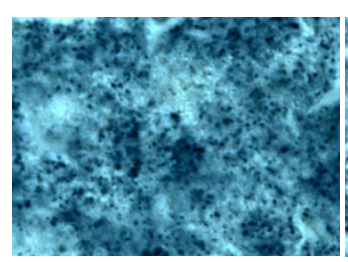

B

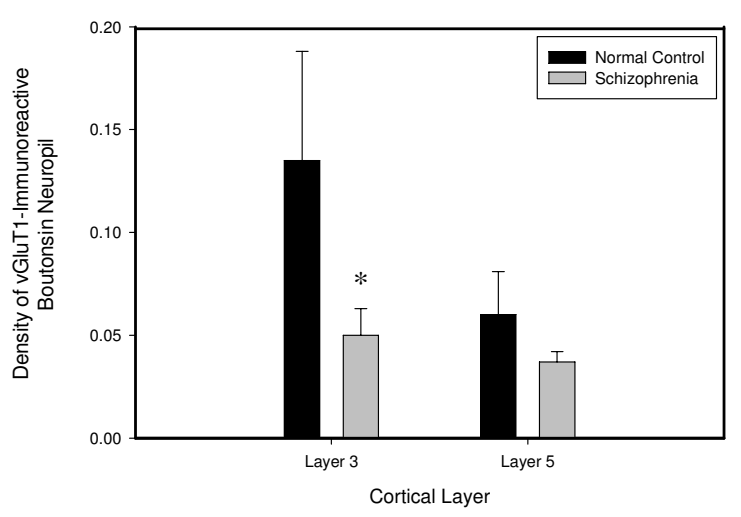

Figure 4

(A) Photomicrographs showing vGluTI-immunoreactive boutons in layer 3 of the PFC. Scale bar $=100$ $\mu \mathrm{m}$. (B) Density of vGluTI-immunoreactive boutons is significantly decreased in layer 3 of the PFC in schizophrenia.

Our observation of reduced vGluT1-immunoreactive boutons in layer 3 indicates that the number of glutamatergic axon terminals may be decreased in schizophrenia. An alternative interpretation of this finding is that the boutons may remain structurally intact (i.e. their number does not change), but they are functionally altered (i.e. vGluT1 expression is reduced). Because dendritic spines are the most common target of glutamatergic terminals [57], and because density of spines on layer 3 pyramidal cells has been found to be decreased by $\sim 20 \%$ in schizophrenia [58], it would appear that our finding of reduced vGluT1 immunoreactivity reflects, at least in part, a loss of axon terminals. However, the magnitude of spine loss of $20 \%$ is insufficient to account for the current observation of a $79 \%$ reduction in vGluT1 immunoreactivity. Because up to $85 \%$ of all asymmetric synapses (i.e. synapses formed by glutamatergic terminals) in the cortex are formed almost exclusively on dendritic spines [59], and this amount is similar to the magnitude of reduction in vGluT1-immunoreactive profiles observed in this study, one interpretation of our finding is that the majority of the glutamatergic terminals that target pyramidal neurons in layer 3 of the PFC are functionally disturbed in schizophrenia and, among these terminals, approximately $20 \%$ are lost. Alternatively, but not mutually exclusively, gluta- 
matergic terminals that target neural structures other than spines may also be affected. Interestingly, aside from dendritic spines, the PV-containing neurons constitute the prime target of these terminals [11]. Given our finding of reduced NR2A expression in these neurons, it seems likely that glutamatergic terminals that are presynaptic to PV neurons may also be disturbed. In order to definitively address this hypothesis, however, double immunolabeling in combination with confocal or electron microscopy will be required.

Deficient glutamatergic inputs to PV neurons could, via disinhibition [60], lead to increased activity of excitatory circuits that are postsynaptic to these neurons, rendering them more vulnerable to excitotoxic or oxidative injury $[8,43,61,62]$. Short of leading to cell death, available evidence suggests that cellular injury can be manifested in the form of neuritic and synaptic atrophy [63-68] and hence may contribute to the observed reduction in dendritic spines [58,69], pyramidal cell somal area [70], synaptic markers [71-76] and volume of neuropil [39] in schizophrenia. In addition, PV neurons are known to play a critical role in the orchestration of oscillation of pyramidal cell circuits in the gamma frequency band (30-100 $\mathrm{Hz}$ ), which is thought to be a mechanism that supports information integration [77-80]. Recent studies increasingly converge upon the notion that gamma oscillation disturbances represent a prominent pathophysiologic feature of schizophrenia [81-83]. In addition, animal studies have shown that NMDA receptor blockade robustly disrupts gamma rhythms in the entorhinal cortex [84] and it is speculated that this disruption may be mediated by the NMDA receptors on the PV-containing neurons [84]. Taken together, reduced glutamatergic inputs onto PV neurons via NMDA receptors may in part contribute to aberrant gamma oscillations in schizophrenia. However, it is important to note that the contribution of NMDA receptor to excitatory neurotransmission onto PV neurons varies across brain regions $[85,86]$. This may explain why the effects of NMDA antagonism on gamma oscillations are highly region-dependent [87].

\section{Conclusion}

Convergent lines of evidence suggest that glutamatergic neurotransmission on PV-containing neurons via NMDA receptors appears to be deficient in schizophrenia. Altered NMDA receptor expression is not restricted to PV neurons. For example, the expression of NR2A mRNA has also been found to be altered in the inhibitory neurons that contain another calcium buffer calbindin [33], which target the dendrites of pyramidal neurons. Likewise, altered glutamate receptor expression in inhibitory neurons is not confined to the NMDA class; the expression of the mRNA for the GluR5 kainate receptor in GABA neurons, for instance, has also been found to be altered [88]. It seems clear that more studies are needed before we can better define how cortical circuits are disturbed in schizophrenia, and the potential functional consequences of these disturbances. Such knowledge will provide a neurobiologic framework within which it may be possible to conceptualize rational therapeutic strategies that aim at normalizing or recalibrating the malfunctioned brain circuits $[89,90]$.

\section{Competing interests}

The authors declare that they have no competing interests.

\section{Authors' contributions}

BKYB and MPL conducted the experiments and the microscopic quantification. JFK assisted in data collection. BKYB performed data analysis. BKYB, TK and TUWW reviewed and discussed the findings. BKYB and TUWW wrote the manuscript. All authors read and approved the final manuscript.

\section{Additional material}

\author{
Additional file 1 \\ Supplementary table S1 \\ Click here for file \\ [http://www.biomedcentral.com/content/supplementary/1471- \\ 244X-9-71-S1.DOC]
}

\section{Acknowledgements}

This study was supported by grants MH076060 and MH06854I from the National Institutes of Health.

\section{References}

I. Fuster JM: The prefrontal cortex. New York: Elsevier; 2008

2. Goldman-Rakic PS: The physiological approach: functional architecture of working memory and disordered cognition in schizophrenia. Biological Psychiatry 1999, 46(5):650-66I.

3. Baddeley AD: Working memory. Oxford: Oxford University Press; 1988.

4. Bowie CR, Harvey PD: Cognition in schizophrenia: impairments, determinants, and functional importance. Psychiatr Clin North Am 2005, 28(3):6I 3-633.

5. Lisman JE, Fellous JM, Wang XJ: A role for NMDA-receptor channels in working memory. Nat Neurosci 1998, I(4):273-275.

6. Tegner J, Compte A, Wang XJ: The dynamical stability of reverberatory neural circuits. Biol Cybern 2002, 87(5-6):47I-48I.

7. Rolls ET, Loh M, Deco G, Winterer G: Computational models of schizophrenia and dopamine modulation in the prefrontal cortex. Nat Rev Neurosci 2008, 9(9):696-709.

8. Lisman JE, Coyle JT, Green RW, Javitt DC, Benes FM, Heckers S, Grace AA: Circuit-based framework for understanding neurotransmitter and risk gene interactions in schizophrenia. Trends Neurosci 2008, 3 I(5):234-242.

9. Wang X-J: A microcircuit model of prefrontal functions: ying and yang of reverberatory neurodynamics in cognition. In The frontal lobes Edited by: Risberg J, Grafnab J. Cambridge: Cambridge University Press; 2006:92-127.

10. Melchitzky DS, Sesack SR, Pucak ML, Lewis DA: Synaptic targets of pyramidal neurons providing intrinsic horizontal connections in monkey prefrontal cortex. Journal of Comparative Neurology 1998, 390(2):21I-224. 
II. Melchitzky DS, Lewis DA: Pyramidal neuron local axon terminals in monkey prefrontal cortex: differential targeting of subclasses of GABA neurons. Cereb Cortex 2003, I3(5):452-460.

12. Barbas $\mathrm{H}$ : Anatomic basis of cognitive-emotional interactions in the primate prefrontal cortex. Neuroscience \& Biobehavioral Reviews 1995, I9(3):499-510.

13. Constantinidis C, Williams GV, Goldman-Rakic PS: A role for inhibition in shaping the temporal flow of information in prefrontal cortex. Nature Neuroscience 2002, 5(2): I75- I 80.

14. Rao SG, Williams GV, Goldman-Rakic PS: Isodirectional tuning of adjacent interneurons and pyramidal cells during working memory: evidence for microcolumnar organization in PFC. Journal of Neurophysiology 1999, 8 I(4): 1903-1916.

15. Akbarian S, Kim JJ, Potkin SG, Hagman JO, Tafazzoli A, Bunney WE Jr, Jones EG: Gene expression for glutamic acid decarboxylase is reduced without loss of neurons in prefrontal cortex of schizophrenics. Archives of General Psychiatry 1995, 52(4):258-266.

16. Benes FM, Berretta S: GABAergic interneurons: implications for understanding schizophrenia and bipolar disorder. Neuropsychopharmacology 200I, 25(I): I-27.

17. Lewis DA, Hashimoto T, Volk DW: Cortical inhibitory neurons and schizophrenia. Nat Rev Neurosci 2005, 6(4):3 I 2-324.

18. Costa E, Davis JM, Dong E, Grayson DR, Guidotti A, Tremolizzo L, Veldic M: A GABAergic cortical deficit dominates schizophrenia pathophysiology. Crit Rev Neurobiol 2004, I 6( I-2): I-23.

19. Woo TUW, Walsh JP, Benes FM: Density of Glutamic Acid Decarboxylase 67 Messenger RNA-Containing Neurons That Express the N-Methyl-D-Aspartate Receptor Subunit NR2A in the Anterior Cingulate Cortex in Schizophrenia and Bipolar Disorder. Arch Gen Psychiatry 2004, 6 I (7):649-657.

20. Woo TUW, Kim AM, Viscidi E: Disease-specific alterations in glutamatergic neurotransmission on inhibitory interneurons in the prefrontal cortex in schizophrenia. Brain Res 2008 | 2 | 8:267-277.

21. Gupta A, Wang Y, Markram H: Organizing principles for a diversity of GABAergic interneurons and synapses in the neocortex. Science 2000, 287(545 I):273-278.

22. Wang XJ, Tegner J, Constantinidis C, Goldman-Rakic PS: Division of labor among distinct subtypes of inhibitory neurons in a cortical microcircuit of working memory. Proc Natl Acad Sci USA 2004, I 0 I(5): | 368-1373.

23. Markram H, Toledo-Rodriguez M, Wang Y, Gupta A, Silberberg G, Wu C: Interneurons of the neocortical inhibitory system. Nat Rev Neurosci 2004, 5( I 0):793-807

24. Freund TF, Katona I: Perisomatic inhibition. Neuron 2007 56(I):33-42

25. DeFelipe J, Farinas I: The pyramidal neuron of the cerebral cortex: morphological and chemical characteristics of the synaptic inputs. Progress in Neurobiology 1992, 39(6):563-607.

26. Hashimoto T, Volk DW, Eggan SM, Mirnics K, Pierri JN, Sun Z, Sampson $A R$, Lewis DA: Gene expression deficits in a subclass of GABA neurons in the prefrontal cortex of subjects with schizophrenia. J Neurosci 2003, 23( I 5):63। 5-6326.

27. Kinney JW, Davis CN, Tabarean I, Conti B, Bartfai T, Behrens MM: A specific role for NR2A-containing NMDA receptors in the maintenance of parvalbumin and GAD67 immunoreactivity in cultured interneurons. I Neurosci 2006, 26(5): I604-16 I5

28. Behrens MM, Ali SS, Dao DN, Lucero J, Shekhtman G, Quick KL, Dugan LL: Ketamine-induced loss of phenotype of fast-spiking interneurons is mediated by NADPH-oxidase. Science 2007 , 3 | 8(5856): | 645-1647.

29. Xi D, Keeler B, Zhang W, Houle JD, Gao WJ: NMDA receptor subunit expression in GABAergic interneurons in the prefrontal cortex: Application of laser microdissection technique. J Neurosci Methods 2008.

30. Kaneko T, Fujiyama F: Complementary distribution of vesicular glutamate transporters in the central nervous system. Neurosci Res 2002, 42(4):243-250.

31. Kaneko T, Fujiyama F, Hioki H: Immunohistochemical localization of candidates for vesicular glutamate transporters in the rat brain. J Comp Neurol 2002, 444(I):39-62.

32. Feighner JP, Robins E, Guze SB, Woodruff RA Jr, Winokur G, Munoz $\mathrm{R}$ : Diagnostic criteria for use in psychiatric research. Arch Gen Psychiatry 1972, 26(I):57-63.

33. Woo TU, Shrestha K, Lamb D, Minns MM, Benes FM: N-Methyl-DAspartate Receptor and Calbindin-Containing Neurons in the Anterior Cingulate Cortex in Schizophrenia and Bipolar Disorder. Biol Psychiatry 2008, 64:803-809.

34. Heckers S, Stone D, Walsh J, Shick J, Koul P, Benes FM: Differential hippocampal expression of glutamic acid decarboxylase 65 and 67 messenger RNA in bipolar disorder and schizophrenia. Arch Gen Psychiatry 2002, 59(6):521-529.

35. Fujiyama F, Furuta T, Kaneko T: Immunocytochemical localization of candidates for vesicular glutamate transporters in the rat cerebral cortex. I Comp Neurol 200I, 435(3):379-387.

36. Fremeau RT Jr, Troyer MD, Pahner I, Nygaard GO, Tran CH, Reimer RJ, Bellocchio EE, Fortin D, Storm-Mathisen J, Edwards RH: The expression of vesicular glutamate transporters defines two classes of excitatory synapse. Neuron 200I, 3 I (2):247-260.

37. Woo TUW, Miller JL, Lewis DA: Schizophrenia and the parvalbumin-containing class of cortical local circuit neurons. American Journal of Psychiatry 1997, I 54(7): I013-1015.

38. Minelli A, Edwards RH, Manzoni T, Conti F: Postnatal development of the glutamate vesicular transporter VGLUT I in rat cerebral cortex. Brain Res Dev Brain Res 2003, I40(2):309-3|4.

39. Selemon LD, Rajkowska G, Goldman-Rakic PS: Abnormally high neuronal density in the schizophrenic cortex. Archives of General Psychiatry 1995, 52(10):805-818

40. Thune |], Uylings HB, Pakkenberg B: No deficit in total number of neurons in the prefrontal cortex in schizophrenics. Journal of Psychiatric Research 200I, 35(I):I5-2I.

41. Javitt DC, Zukin SR: Recent advances in the phencyclidine model of schizophrenia. Am J Psychiatry 1991, |48( I 0): | 30|- | 308.

42. Krystal JH, Karper LP, Seibyl JP, Freeman GK, Delaney R, Bremner JD, Heninger GR, Bowers MB Jr, Charney DS: Subanesthetic effects of the noncompetitive NMDA antagonist, ketamine, in humans. Arch Gen Psychiatry 1994, 5 I (3): | 99-2।4

43. Olney JW, Farber NB: Glutamate receptor dysfunction and schizophrenia. Arch Gen Psychiatry 1995, 52(12):998-1007.

44. Greene R, Bergeron R, McCarley R, Coyle JT, Grunze H: Shortterm and long-term effects of $\mathbf{N}$-methyl-D-aspartate receptor hypofunction. Arch Gen Psychiatry 2000, 57(12):||180-II8I. author reply I I82-I I83

45. Grunze HC, Rainnie DG, Hasselmo ME, Barkai E, Hearn EF, McCarley RW, Greene RW: NMDA-dependent modulation of CAI local circuit inhibition. J Neurosci 1996, I 6(6):2034-2043.

46. Abdul-Monim Z, Neill JC, Reynolds GP: Sub-chronic psychotomimetic phencyclidine induces deficits in reversal learning and alterations in parvalbumin-immunoreactive expression in the rat. I Psychopharmacol 2007, 2 I(2):198-205.

47. Rujescu D, Bender A, Keck M, Hartmann AM, Ohl F, Raeder H, Giegling I, Genius ], McCarley RW, Moller HJ, et al:: A pharmacological model for psychosis based on $\mathbf{N}$-methyl-D-aspartate receptor hypofunction: molecular, cellular, functional and behavioral abnormalities. Biol Psychiatry 2006, 59(8):721-729.

48. Keilhoff G, Becker A, Grecksch G, Wolf G, Bernstein HG: Repeated application of ketamine to rats induces changes in the hippocampal expression of parvalbumin, neuronal nitric oxide synthase and cFOS similar to those found in human schizophrenia. Neuroscience 2004, I 26(3):591-598.

49. Morrow BA, Elsworth JD, Roth RH: Repeated phencyclidine in monkeys results in loss of parvalbumin-containing axoaxonic projections in the prefrontal cortex. Psychopharmacology (Berl) 2007, I 92(2):283-290.

50. Woo TUW, Whitehead RE, Melchitzky DS, Lewis DA: A subclass of prefrontal gamma-aminobutyric acid axon terminals are selectively altered in schizophrenia. Proceedings of the National Academy of Sciences of the United States of America 1998, 95(9):534|-5346.

5I. Konopaske GT, Sweet RA, Wu Q, Sampson A, Lewis DA: Regional specificity of chandelier neuron axon terminal alterations in schizophrenia. Neuroscience 2006, I38(I):189-196.

52. Pierri JN, Chaudry AS, Woo TU, Lewis DA: Alterations in chandelier neuron axon terminals in the prefrontal cortex of schizophrenic subjects. American Journal of Psychiatry 1999 I56(II): I709-1719.

53. Eastwood SL, Harrison PJ: Decreased expression of vesicular glutamate transporter I and complexin II mRNAs in schizophrenia: further evidence for a synaptic pathology affecting glutamate neurons. Schizophr Res 2005, 73(2-3): I59-I72. 
54. Oni-Orisan A, Kristiansen LV, Haroutunian V, Meador-Woodruff JH, McCullumsmith RE: Altered vesicular glutamate transporter expression in the anterior cingulate cortex in schizophrenia. Biol Psychiatry 2008, 63(8):766-775.

55. Stefansson H, Sigurdsson E, Steinthorsdottir V, Bjornsdottir S, Sigmundsson T, Ghosh S, Brynjolfsson J, Gunnarsdottir S, Ivarsson O, Chou TT, et al.: Neuregulin I and susceptibility to schizophrenia. Am J Hum Genet 2002, 7 I (4):877-892.

56. Reynolds GP, Harte MK: The neuronal pathology of schizophrenia: molecules and mechanisms. Biochem Soc Trans 2007, 35(Pt 2):433-436.

57. Melchitzky DS, Gonzalez-Burgos G, Barrionuevo G, Lewis DA: Synaptic targets of the intrinsic axon collaterals of supragranular pyramidal neurons in monkey prefrontal cortex. Journal of Comparative Neurology 200I, 430(2):209-22I.

58. Glantz LA, Lewis DA: Decreased dendritic spine density on prefrontal cortical pyramidal neurons in schizophrenia. Archives of General Psychiatry 2000, 57( I):65-73.

59. Braitenberg V, Schuz A: Cortex: Statistics and geometry of neuronal connectivity. New York: Berlin; 1998.

60. Homayoun H, Moghaddam B: NMDA receptor hypofunction produces opposite effects on prefrontal cortex interneurons and pyramidal neurons. I Neurosci 2007, 27(43): | | 496- | I 500.

61. Deutsch SI, Rosse RB, Schwartz BL, Mastropaolo J: A revised excitotoxic hypothesis of schizophrenia: therapeutic implications. Clin Neuropharmacol 200I, 24(I):43-49.

62. Coyle JT: The GABA-glutamate connection in schizophrenia: which is the proximate cause? Biochem Pharmacol 2004 68(8): $|507-| 5 \mid 4$.

63. Glantz LA, Gilmore JH, Lieberman JA, Jarskog LF: Apoptotic mechanisms and the synaptic pathology of schizophrenia. Schizophr Res 2006, 8 I (I):47-63.

64. Jarskog LF, Glantz LA, Gilmore JH, Lieberman JA: Apoptotic mechanisms in the pathophysiology of schizophrenia. Prog Neuropsychopharmacol Biol Psychiatry 2005, 29(5):846-858.

65. Bernstein M, Lichtman JW: Axonal atrophy: the retraction reaction. Curr Opin Neurobiol 1999, 9(3):364-370.

66. Gilman CP, Mattson MP: Do apoptotic mechanisms regulate synaptic plasticity and growth-cone motility? Neuromolecular Med 2002, 2(2): |97-2|4.

67. Garden GA, Budd SL, Tsai E, Hanson L, Kaul M, D'Emilia DM, Friedlander RM, Yuan J, Masliah E, Lipton SA: Caspase cascades in human immunodeficiency virus-associated neurodegeneration. J Neurosci 2002, 22(1 0):4015-4024.

68. Mattson MP, Keller JN, Begley JG: Evidence for synaptic apoptosis. Exp Neurol 1998, I 53(I):35-48.

69. Garey LJ, Ong WY, Patel TS, Kanani M, Davis A, Mortimer AM, Barnes TR, Hirsch SR: Reduced dendritic spine density on cerebral cortical pyramidal neurons in schizophrenia. Journal of Neurology, Neurosurgery \& Psychiatry 1998, 65(4):446-453.

70. Pierri JN, Volk CL, Auh S, Sampson A, Lewis DA: Decreased somal size of deep layer 3 pyramidal neurons in the prefrontal cortex of subjects with schizophrenia. Archives of General Psychiatry 200I, 58(5):466-473.

7I. Eastwood SL, Burnet PW, Harrison PJ: Altered synaptophysin expression as a marker of synaptic pathology in schizophrenia. Neuroscience 1995, 66(2):309-319.

72. Glantz LA, Lewis DA: Reduction of synaptophysin immunoreactivity in the prefrontal cortex of subjects with schizophrenia. Archives of General Psychiatry 1997, 54(7):660-669.

73. Halim ND, Weickert CS, McClintock BW, Hyde TM, Weinberger DR, Kleinman JE, Lipska BK: Presynaptic proteins in the prefrontal cortex of patients with schizophrenia and rats with abnormal prefrontal development. Mol Psychiatry 2003, 8(9):797-8I0.

74. Honer WG, Falkai P, Bayer TA, Xie J, Hu L, Li HY, Arango V, Mann J, Dwork AJ, Trimble WS: Abnormalities of SNARE mechanism proteins in anterior frontal cortex in severe mental illness. Cereb Cortex 2002, I 2(4):349-356.

75. Davidsson P, Gottfries J, Bogdanovic N, Ekman R, Karlsson I, Gottfries $C G$, Blennow $K$ : The synaptic-vesicle-specific proteins rab3a and synaptophysin are reduced in thalamus and related cortical brain regions in schizophrenic brains. Schizophrenia Research 1999, 40(1):23-29.

76. Sawada K, Young CE, Barr AM, Longworth K, Takahashi S, Arango V, Mann JJ, Dwork AJ, Falkai P, Phillips AG, et al.: Altered immunore- activity of complexin protein in prefrontal cortex in severe mental illness. Mol Psychiatry 2002, 7(5):484-492.

77. Uhlhaas PJ, Singer W: Neural synchrony in brain disorders: relevance for cognitive dysfunctions and pathophysiology. Neuron 2006, 52(I): I55-168.

78. Engel AK, Singer W: Temporal binding and the neural correlates of sensory awareness. Trends Cogn Sci 200I, 5(I): I6-25.

79. Singer W, Gray C, Engel A, Konig P, Artola A, Brocher S: Formation of cortical cell assemblies. Cold Spring Harb Symp Quant Biol 1990, 55:939-952.

80. Tallon-Baudry C: Attention and awareness in synchrony. Trends Cogn Sci 2004, 8(1 2):523-525.

81. Uhlhaas PJ, Haenschel C, Nikolic D, Singer W: The role of oscillations and synchrony in cortical networks and their putative relevance for the pathophysiology of schizophrenia. Schizophr Bull 2008, 34(5):927-943.

82. Spencer KM: Visual gamma oscillations in schizophrenia: implications for understanding neural circuitry abnormalities. Clin EEG Neurosci 2008, 39(2):65-68.

83. Ford JM, Krystal JH, Mathalon DH: Neural synchrony in schizophrenia: from networks to new treatments. Schizophr Bull 2007, 33(4):848-852.

84. Cunningham MO, Hunt J, Middleton S, LeBeau FE, Gillies MJ, Davies $\mathrm{CH}$, Maycox PR, Whittington MA, Racca C: Region-specific reduction in entorhinal gamma oscillations and parvalbuminimmunoreactive neurons in animal models of psychiatric illness. J Neurosci 2006, 26(1 0):2767-2776.

85. Huntley GW, Vickers JC, Janssen W, Brose N, Heinemann SF, Morrison $\mathrm{JH}$ : Distribution and synaptic localization of immunocytochemically identified NMDA receptor subunit proteins in sensory-motor and visual cortices of monkey and human. Neurosci 1994, I4(6):3603-3619.

86. Nyiri G, Stephenson FA, Freund TF, Somogyi P: Large variability in synaptic $\mathbf{N}$-methyl-D-aspartate receptor density on interneurons and a comparison with pyramidal-cell spines in the rat hippocampus. Neuroscience 2003, I I 9(2):347-363.

87. Roopun AK, Cunningham MO, Racca C, Alter K, Traub RD, Whittington MA: Region-Specific Changes in Gamma and Beta2 Rhythms in NMDA Receptor Dysfunction Models of Schizophrenia. Schizophr Bull 2008, 34(5):962-973.

88. Woo TUW, Shrestha K, Amstrong C, Minns MM, Walsh JP, Benes FM: Differential alterations of kainate receptor subunits in inhibitory interneurons in the anterior cingulate cortex in schizophrenia and bipolar disorder. Schizophr Res 2007, 96(I3):46-6I.

89. Hyman SE, Fenton WS: Medicine. What are the right targets for psychopharmacology? Science 2003, 299(5605):350-35I.

90. Lewis DA, Gonzalez-Burgos G: Pathophysiologically based treatment interventions in schizophrenia. Nat Med 2006, 12(9): $1016-1022$

\section{Pre-publication history}

The pre-publication history for this paper can be accessed here:

http://www.biomedcentral.com/1471-244X/9/71/pre pub 